\title{
On the Crush Behavior of an Ultra Light Multi-Cell Foam-Filled Composite Structure under Axial Compression
}

\begin{abstract}
In this article the results of experimental works pertaining to the crash behavior and crashworthiness characteristics of a novel multi-cell cost-effective crashworthy composite sandwich structure are presented. All the samples are based on the concept of the triplelayered' foam-filled block, i.e., three polyurethane foam core sheets, which are wrapped by reinforcement fiberglass woven fabric, that acts as the reinforcement face and meanwhile ties the foam layers and faces together, thus preventing catastrophic failure. The design, manufacturing, and crush testing of rectangular blocks are described. Experimental results indicate an efficient progressive collapse mechanism with high values of crushing force efficiency and specific energy absorption.
\end{abstract}

